Reprod. Nutr. Dévelop., 1980, 20 (3 B), 791-800.

\title{
Hormonal and nonhormonal regulation of maternal behavior : A theoretical survey
}

\author{
par J. S. ROSENBLATT
}

Institufe of Animal Behavior, Rutgers University

101 Warren Street, Newark, New Jersey 07102 U.S.A.

\begin{abstract}
Summary. There is a general uniformity in the hormones that regulate pregnancy among a large variety of mammals. There is also a division of maternal behavior into two main patterns : that shown by mammals that build nests for the altricial young and those that only briefly establish a birth sife for the precocial young. Apart from this difference, the patterns of maternal behavior are quite similar, centering around nursing, and weaning follows a similar course in different species. Is there a corresponding uniformity in the factors which regulate maternal behavior?

Too few species have been studied to establish any general rule about the hormonal basis for the onset of maternal behavior. In the main, however, the ovarian hormones probably play a major role in most species and prolactin appears to play a role in at least one species.

Post-parfum maternal behavior appears to depend mainly upon stimulation from the young and hormones may not be required to maintain it or be involved in its decline.

The transition period between hormonal and nonhormonal regulation of maternal behavior may emerge as an important phenomenon in many species.
\end{abstract}

There is a general similarity in pre- and post-partum features of the maternal behavior cycle in a variety of mammals, particularly in the hormone patterns that regulate pregnancy and initiate parturition. This poses the problem of whether in these species there is a corresponding similarity in the hormonal basis of maternal behavior. Among nearly all mammals the onset of maternal behavior coincides with a decline in circulating levels of progesterone, and rises in both estrogen and prolactin. However, not all of these hormonal changes need be crucial for the onset of maternal behavior ; they may be involved in either the termination of pregnancy and the triggering of parturition or the onset of lactation, all of which are synchronized with the onset of maternal behavior. In the first section of this paper I shall review studies on the rat, mouse, hamster and rabbit in which studies have been done on the hormonal basis of maternal behavior.

Our studies on the post-partum maternal behavior of the rat, and those of Koller (1956) in the mouse, have suggested that there is a shift in the regulation of maternal behavior after parturition. There is a dramatic change in the pattern of hormonal secretions following parturition and while it might be supposed that maternal beha- 
vior is maintained, perhaps, by hormones of the lactogenic complex, chiefly prolactin, as has been proposed in the past, nevertheless there is strong evidence in the rat that maternal behavior is regulated on a nonhormonal basis after parturition and is dependent mainly upon stimulation from the young (Rosenblatt, 1975).

There are reasons to believe that this shift in the regulation of maternal behavior from a hormonal to a nonhormonal basis may have evolved among mammals as a means of speeding reproduction, by freeing the endocrine system to initiate a second reproductive cycle while completing the behavioral and lactational phase of the first cycle (Rosenblatt et al., 1979). We shall review the evidence in the rat for this conception and examine evidence in other species that bear on this problem.

The shift in regulation of maternal behavior from pre- to post-partum, which, it is proposed, represents a shift from a hormonal to a nonhormonal basis (i. e., stimuli from the young, chiefly) creates a transition period that is, itself, of considerable imporfance. As the hormonal stimulation which initiates maternal behavior wanes sensory stimulation grows in strength and eventually gains control of maternal behavior. We shall discuss this period in a separate section.

A. - Patterns of hormonal secretion at the termination of pregnancy and the onset of maternal behavior.

The pattern of circulating ovarian hormones, and, in several species, the anterior pituitary hormones, particularly, prolactin, during pregnancy, are shown in figures 1 through 4. The rat, rabbit, and mouse show similar patterns characterized, as noted above, by a terminal decline in circulating progesterone, a rise in estrogen and a subsequent rise in prolactin. The hamster differs in exhibiting terminal declines in circulating levels of both progesterone and estrogen (which may also emerge as the pattern in the dog) although prolactin rises slightly at the end of pregnancy. In this species too, estrogen levels throughout pregnancy are considerably higher than in other species. Although there are some variations in this general pattern of hormonal secretions during pregnancy in species such as the dog, cat, guinea pig, and among the ungulates, there is sufficient similarity to suggest that findings in these laboratory species are likely to shed light on the hormonal basis of maternal behavior in these other species.

\section{B. - Hormonal basis of maternal behavior in the rat.}

It is difficult to intervene in the normal pattern of hormone secretion at the end of pregnancy in the rat without altering the entire pattern of hormone secretion, not just the secretion of one hormone, and without interfering with the birth process itself. We have shown, using single injections of blood plasma taken from recently postpartum mothers, and by cross-transfusing blood between new mothers and nonpregnant infact females, that short-latency maternal behavior can be induced by some humoral factor(s) which presumably is acting on the mother herself at this time or possibly earlier (Terkel and Rosenblatt, 1968, 1972). The method of extended systemic injections of progesterone, estradiol benzoate, and prolactin, lasting either 12 or 22 days in ovariectomized female rats was used to simulate the hormonal pattern during normal pregnancy and at its termination, by two teams of researchers (Moltz 
et al., 1970 ; Zarrow et al., 1971) both of whom reported successful induction of maternal behavior with short latencies ranging from an almost immediate response to young to 35-40 $\mathrm{hr}$ latencies. The difficulty here is that the particular aspects of the procedure which were effective were not isolated although it was suggested that the decline in progesterone primed the neural substrate of maternal behavior to respond to estrogen and prolactin.

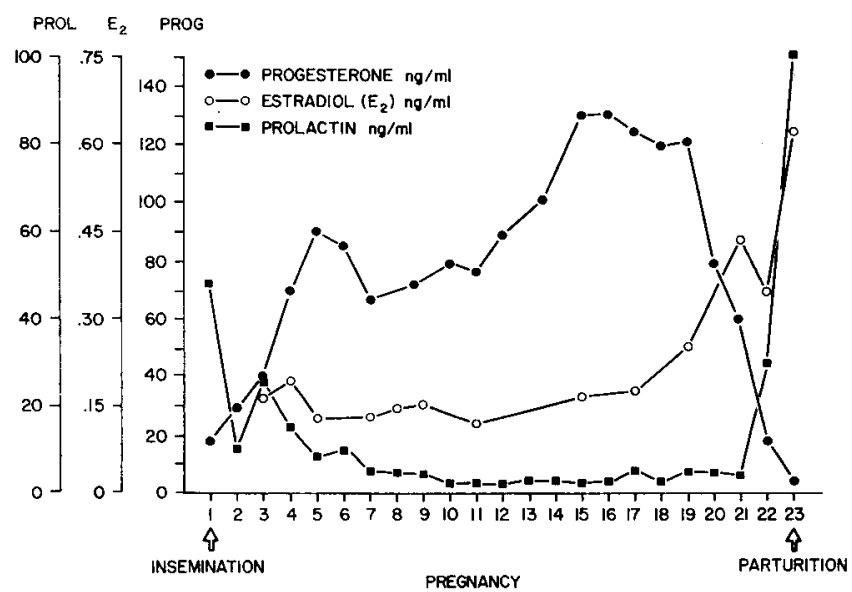

FIG. 1. - Circulating levels of progesterone, estradiol $\left(E_{2}\right)$ and prolactin during pregnancy in the rat. Taken from : progesterone : Pepe and Rothchild (1974); estradiol : Shaikh (1971) ; prolactin : Morishige ef al. (1973).

We have employed hysterectomy-induced maternal behavior in late-pregnant females as a procedure to investigate the hormonal basis and have been able to show that the short-latency maternal behavior that appears after hysterectomy (i. e., 48-72 hrs) is based upon estradiol and can be restored in ovariectomized females by injecting small amounts of estradiol benzoate systemically or by implanting estradiol benzoate in the medial preoptic region of the hypothalamus (Numan ef al., 1977 ; Rosenblatt and Siegel, 1975 ; Siegel and Rosenblatt, 1975 a). Non-pregnant females also respond to estradiol benzoate (after ovariectomy and hysterectomy) by exhibiting short latency maternal behavior (Siegel and Rosenblatt, 1975b).

Since estrogen stimulates the release of prolactin in the animals we have studied it was necessary to rule out this hormone as playing a role in maternal behavior especially since it has long been believed that prolactin is the « maternal hormone ». This was done by using pharmacological agents that block the release of prolactin(i. e., ergocornine hydrogen maleate, ergokryptine (CB 154-2- bromo-alpha-ergokryptine), and apomorphine hydrochloride). In three separate experiments we have shown that blocking the release of prolactin does not prevent estrogen-stimulated maternal behavior (Numan et al., 1977). Stern (1977) and Zarrow ef al. (1971) have shown that blocking the release of prolactin during the last 4 days of pregnancy also does not prevent the onset of maternal behavior.

The role of progesterone in the onset of maternal behavior is more complex and requires some discussion. Normally this hormone declines about 30 hrs before partu- 
rition and we have found that this is a necessary condition for estrogen stimulation of maternal behavior. If progesterone is given to estrogen-treated females it blocks the onset of maternal behavior when given $24 \mathrm{hr}$ after the estrogen but has no effect if given $\mathbf{4 4} \mathrm{hr}$ after estrogen and only a slight effect if given at the same time as the estrogen (Siegel and Rosenblatt, 1975c, 1978 ; Siegel et al., 1978).

The decline of progesterone appears, in addition, to have more than a permissive effect on estrogen stimulation : in itself it appears to cause a brief period of facilitation of maternal behavior that can be detected by testing females in the interval between hysterectomy-ovariectomy (at the 17th day of pregnancy) and the end of the first $48 \mathrm{hrs}$ (Bridges ef al., 1978).

\section{C. - Hormonal basis of maternal behavior in other species.}

Despite the similarity of hormonal patterns during pregnancy and at parturition, there appears to be no uniformity in the hormonal basis for the onset of maternal behavior in the few species for which we have experimental evidence.

In an extended series of studies, Zarrow and his colleagues (Zarrow ef al., 1971) have found that prolactin is an essential hormone for stimulating the onset of maternal nestbuilding in rabbits. Normally the terminal release of large amounts of prolactin is preceded by prolonged stimulation by progesterone and estrogen with a decline in progesterone occurring shortly before parturition. Normal pregnancies in which females were either hypophysectomized or treated with ergocornine hydrogen maleate to block the release of prolactin did not result in maternal nestbuilding ; prolactin replacement therapy restored this behavior, however. The contribution of the preceding progesterone/estrogen stimulation has not been determined though it seems important since pregnancies must be in progress for several weeks before the experimental termination by various means (i. e., ovariectomy, caesarean-section, etc.) which cause the release of prolactin is able to stimulate the onset of maternal nestbuilding. The decline in progesterone does not seem to be effective by itself but it may play a permissive role as in the rat.

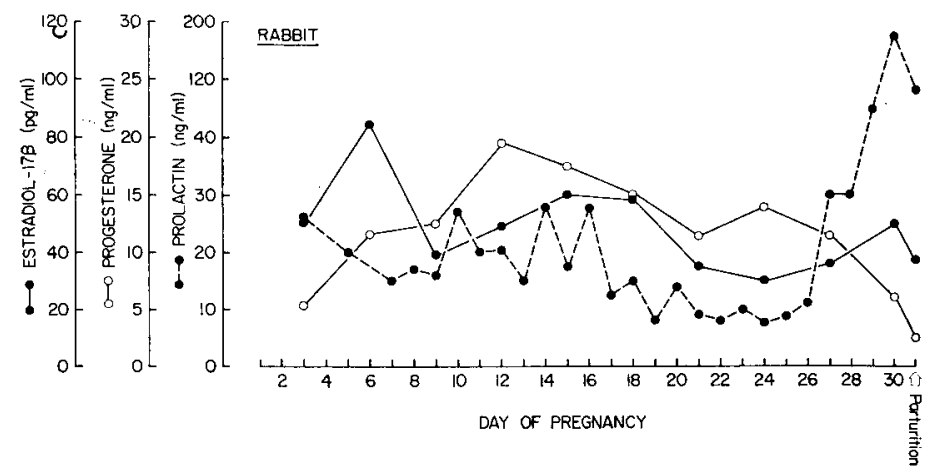

FIG. 2. - Circulating levels of progesterone, estradiol $\left(E_{2}\right)$ and prolactin during pregnancy in the rabbit. Taken from : prolactin : McNeilly and Friesen (1978); estradiol-17 $\beta$, progesterone : Challis, Davies and Ryan (1973). 
In the mouse maternal behavior is largely nonhormonally stimulated (Noirot, 1972) and all females and males readily respond to young pups by exhibiting nestbuilding, retrieving, and licking and by adopting a nursing position. Nevertheless hormones do play a role but somewhat differently than in either the rat or rabbit. Maternal nestbuilding begins early in pregnancy in the mouse and is associated with a rise in circulating levels of progesterone shortly after pregnancy is established. Lisk (1971) has shown that the rise in progesterone stimulates maternal nestbuilding bu that it acts synergistically with low levels of circulating estrogen. At high levels of estrogen, progesterone stimulation is blocked and nestbuilding is either reduced or absent. The nestbuilding seen during pregnancy in the mouse is therefore hormonally-based but that which appears after parturition, following increased circulating levels of estrogen, may be largely nonhormonal.

Even post-partum maternal behavior in the mouse may have a hormonal influence although it is in the form of enhancement of maternal behavior rather than its initiation. Voci and Carlson (1973) reported that prolactin implanted into the hypothalamus of intact virgin females increased the speed of retrieving and shortened its latency whereas both prolactin and progesterone implants increased the amount of nestbuilding. While these findings are probably valid, the use of ovariectomized females would have enabled the results to be attributed, more confidently, to the hormones that were administered rather to possible effects which these may have had on other ovarian and pituitary hormones.
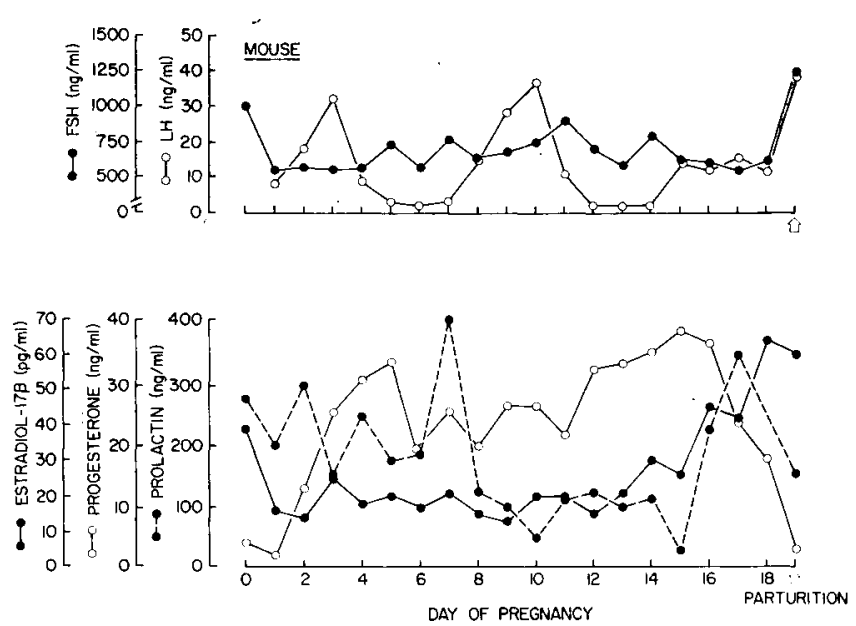

FIG. 3. - Circulating levels of FSH and $\mathrm{LH}$ (upper figure) and progesterone, estradiol $\left(\mathrm{E}_{2}\right)$ and prolactin (bottom figure) during pregnancy in the mouse. Taken from : LH, FSH : Murr, Bradford and Geschwind (1974); progesterone, estradiol-17 $\beta$ : McCormack and Greenwald (1974).

As in the rat, maternal behavior begins pre-partum in the hamster (if females are tested during the last 25 hrs by being presented with newborn pups) and it has been found that preventing the decline of either progesterone or estradiol does not prevent the pre-partum onset (Siegel and Greenwald, 1975). Hysterectomy during late 
pregnancy, which is effective in the rat and rabbit, does not stimulate maternal behavior in the hamster.

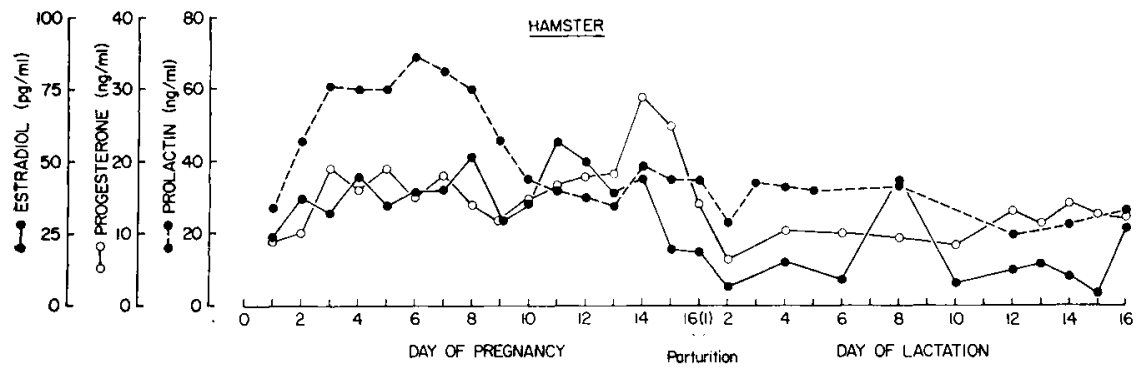

FIG. 4. - Circulating levels of progesterone, estradiol $\left(\mathrm{E}_{2}\right)$, and prolactin during pregnancy in the hamster. Post-partum levels are also shown. Taken from : prolactin : Bast and Greenwald (1974) ; estradiol, progesterone : Baranczuk and Greenwald (1974).

Only nestbuilding has been successfully stimulated in nonpregnant ovariectomized hamsters by implanting progesterone and estrogen subcutaneously for a period of about 18 days. Between the 12th and 16th day of implantation there is a rise in nestbuilding equal to that which occurs at the end of pregnancy (i. e., day 16 of pregnancy). Since the rise occurs even before the hormones are withdrawn, this suggests that, at least whith respect to nestbuilding, it may be the prolonged action of these two hormones and possibly pituitary hormone(s) (e. g., prolactin) which stimulate this aspect of maternal behavior and possibly other aspects as well (Richards, 1969).

D. - Post-partum regulation of maternal behavior in the rat.

The evidence that maternal behavior in the post-partum rat may be nonhormonally regulated comes from three sources (Rosenblatt, 1975) :1) Immediately post-partum the hormone picture changes drastically as the female initiates a single estrous cycle yet this does not interfere with her maternal behavior. Moreover, hypophysectomy and ovariectomy, as well as blocking prolactin release are without effect on maternal behavior post-partum and the injection of progesterone, which normally blocks the onset of maternal behavior, has no effect post-partum. 2) On the other hand, removal of the pups at parturition results in a rapid decline in maternal behavior over the next 2 to 4 days. Throughout the post-partum period, maternal behavior is regulated by the characteristics of pups, particularly the age of the litter which the mother aftends. Maternal behavior can be revived and prolonged by giving mothers, in the process of weaning their own young, pups less than a week old, and it can be partially terminated prematurely by giving mothers older litters. 3) Maternal behavior can be elicited from nonpregnant, cycling females by exposing them to young pups for a period fo 4 to 6 days. The behavior which is exhibited by these « sensitized 》 females resembles very closely in most respects (excluding maternal aggression toward intruders) that of lactating mothers that have given birth to young. It appears in hypophysectomized and ovariectomized females indicating that it is not based upon hormones released in response to pup stimulation. The above evidence has been presented more extensively in Rosenblatt et al. (1979). 
E. - Post-partum regulation of maternal behavior in other species.

Evidence of post-parfum regulation of maternal behavior by pup stimulation is available in only a few species because of the paucity of experiments directed specifically at this problem.

In the hamster, maternal behavior rapidly declines over the first 5 days if pups are removed from females $1 \mathrm{hr}$ after birth (Siegel and Greenwald, 1978) but if the female is allowed $48 \mathrm{hrs}$ of contact with her pups after birth, maternal behavior is maintained until nearly the normal time of weaning. After parturition the length of the maternal behavior cycle is largely determined by the age of the pups and it can be extended for several weeks by providing females with younger pups at a time when they would normally be weaning their own litter. While this evidence, and the fact that nonpregnant females will retrieve 6-day old pups, is not conclusive evidence of nonhormonal regulation of maternal behavior post-partum, it strongly suggests that this is the case in the hamster.

Of course there is a strong case for nonhormonal regulation of maternal behavior post-partum in the mouse since nonpregnant females are readily maternal under varied hormonal conditions. Moreover, Leblond (1940) and Leblond and Nelson (1937) found that once maternal behavior had appeared post-partum, females could be hypophysectomized and they would continue to exhibit this behavior.

F. - Transition between hormonal and nonhormonal regulation of maternal behavior.

One implication of the shift in the basis of maternal behavior from hormonal stimulation to pup stimulation is that there is a transition period during which the hormonal effects reach a maximum then begin to wane and the stimulus effects are at first weak but increase in strength until they predominate. In the rat we believe this transition phase lasts from $24 \mathrm{hrs}$ before parturition to several days after parturition (Rosenblatt, 1975 ; Rosenblatt et al., 1979) but this may vary in different species and may be complicated by the introduction of a mutually specific bond between the mother and her young.

Bridges $(1975,1977)$ has shown long-term (i. e., 25 days after the last contact with pups) retention of maternal responsiveness in post-partum female rats that have had as litfle as 4-6 hrs contact with their young. The process of transition begins during parturition itself, as Bridges has shown, since females allowed contact with only half of their litter during parturition retain the effects while those that give birth (i. e., therefore, presumably, are hormonally stimulated) but are not permitted contact with their young during parturition, show no effects of having been stimulated hormonally when tested 25 days later.

In the hamster, as we have seen, 24 hrs of post-partum contact enables females to maintain their responsiveness to pups for 4 to 5 days but $48 \mathrm{hrs}$ of post-partum contact allows them to maintain their responsiveness for the next 12 days (Siegel and Greenwald, 1978).

\section{G. - Concluding remarks.}

It is clear in the species we have surveyed that maternal behavior arises out of the hormonal processes which govern pregnancy and particularly those which are 
involved in the termination of pregnancy, the onset of labor and the initiation of lactation. There is little reason to doubt that this is not true for all mammalian species since these three events need to be synchronized if reproduction is to occur. The gestating phase must be completed and the young delivered, but at their delivery the mother must be ready to take care of them and to feed them.

Primates do not differ, in this respect, from the species we have been discussing and the hormonal patterns of pregnancy at least in the rhesus monkey, chimpanzee, and the human, bear a strong resemblance to those in the former species with respect to changes during the terminal phase in circulating levels of progesterone, and prolactin. The possible variety of hormonal mechanisms for initiating maternal behavior even in the few species for which we have evidence should make us very cautious, however, about drawing conclusions from the hormonal picture alone.

Of interest is a growing recognition in the literature on human mother-infant relationship of the importance of the initial contact between the mother and her infant for the formation of this relationship and for the maintenance of the mother's maternal responsiveness (MacFarlane, 1977). Although this literature has been influenced by the animal research, particularly that on the "critical period » for the formation of the mother-young bond in goats and sheep, it has its origins also more directly in human experience. Mothers bearing infants of high risk (i. e., premature infants) and mothers carrying contagious diseases, which force them to be separated from their infants for a long period after delivery, were found to have lost a good deal of their maternal responsiveness by the time they were able to rejoin their infants. This represents, $I$ believe, a failure to have had the opportunity to make the transition from hormonal to stimulus-dependent maternal behavior, among humans. The relative brief separation and infrequent contact between mothers and their infants during the post-partum period, which is the normal routine in many hospitals is now being investigated for its short-term as well as long-term effects on the quality of the relationship. Let me conclude by saying that we are at the beginning of our study of maternal behavior among the mammals, which is surprising at this late date, considering the importance of this aspect of the reproductive process as a measure of the fitness of all other behavioral and physiological adaptations, and considering the crucial role it plays in the development of all members of the species. It is a hopeful sign, however, that, once having been begun, the study of maternal behavior is occurring along a broad front with consideration given to physiological, psychological, and social factors, and with due regard to species differences in all of these aspects.

Colloque "La relation parentale" Nouzilly, France, juin 1979.

Acknowledgments. - This article was written while the author was a guest scientist at I.N.R.A., Station Centrale de Physiologie Animale, Jouy-en-Josas, France and was supported by USPHS Grant MH-08604. Publication number 350 of the Institute of Animal Behavior, Rutgers. The State University of New Jersey. My thanks to C. Banas for the illustrations and to $W$. Cunningham for the secretarial work.

Résumé. Il existe une uniformité générale dans l'équilibre hormonal de la gestation dans une large variété de mammifères. Il apparaît une division du comportement maternel 
en deux catégories : ceux où est construit un nid pour des jeunes peu développés ef ceux où n'existe qu'un lieu de parturition dont l'occupation est brève et où le jeune est précocement autonome. Cette différence mise à part, les manifestations du comportement maternel sont presque similaires, axées sur l'allaitement, et le sevrage suit une évolution similaire dans des espèces différentes. Y correspond-il une uniformité dans les facteurs de régulation du comportement maternel ?

Trop peu d'espèces ont été étudiées pour qu'il soit possible d'établir une règle générale sur les mécanismes de mise en œuvre du comportement maternel. Il semble, cependant, que les hormones ovariennes jouent un rôle majeur dans la plupart des espèces, tandis que la prolactine intervient au moins dans un cas.

Le comportement maternel post-partum semble dépendre principalement de la stimulation des jeunes, les hormones peuvent ne plus être nécessaires pour son maintien ni être impliquées dans sa disparition.

La transition entre les régulations hormonales ef non hormonales se dégage comme un phénomène important dons maintes espèces.

\section{References}

BARANCZUK R., GREENWALD G. S., 1974. Plasma levels of oestrogen and protesterone in pregnant and lactating hamsters. J. Endocr., 63, 125-135.

BAST J. D., GREENWALD G. S., 1974. Daily concentrations of gonadotrophins and prolactin in the serum of pregnant or lactating hamsters. J. Endocr., 63, 527-532.

BRIDGES R. S., 1975. Long-term effects of pregnancy and parturition upon maternal responsiveness in the rat. Physiol. Behav., 14, 245-249.

BRIDGES R. S., 1977. Parturition : its role in the long term retention of maternal behavior in the rat. Physiol. Behav., 18, 487-490.

BRIDGES R. S., ROSENBLATT J. S., FEDER H. H., 1978. Stimulation of maternal responsiveness after pregnancy termination in rats : effect of time of onsel of behavior testing. Horm. Behav., 10, 235-245.

CHALLIS J. R. G., DAVIES I. J., RYAN K. J., 1973. The concentrations of progesterone, estrone and estradiol-17 beta in the plasma of pregnant rabbits. Endocrinology, 93, 971-976.

KOLLER G., 1956. Hormonale und psychische Steuerung beim Nestbau weiser Mause. Zool. Anz. (Suppl.), 19 (Vehr. dtsch. zool. Ges. 1955), 123-132.

LEBLOND C. P., 1940. Nervous and hormonal factors in the maternal behavior of the mouse. J. Genet. Psychol., 57, 327-344.

LEBLOND C. P., NELSON W. O., 1937. Maternal behavior in hypophysectomized male and female mice. Amer. J. Physiol., 120, 167-172.

LISK R. D., 1971. Oestrogen and progesterone synergism and elicitation of maternal nest-building in the mouse (Mus musculus). Anim. Behav., 19, 606-610.

MacFARLANE A., 1977. The psychology of childbirth. Harvard Univ. Press, Cambridge, Mass.

MCCORMACK J. T., GREENWALD G. S., 1974. Progesterone and oestradiol-17 beta concentrations in the peripheral plasma during pregnancy in the mouse. J. Endocr., 62, 101-107.

McNEILLY A. S., FRIESEN H. G., 1978. Prolactin during pregnancy and lactation in the rabbit. Endocrinology, 102, 1548-1554.

MOLTZ H., LUBIN M., LEON M., NUMAN M., 1970. Hormonal induction of maternal behavior in the ovariectomized nulliparous rat. Physiol. Behav., 5, 1373-1377.

MORISHIGE W. K., PEPE G., ROTHCHILD I., 1973. Serum luteinizing hormone (LH), prolactin and progesterone levels during pregnancy in the rat. Endocrinology, 92, 1527-1530.

MURR S. M., BRADFORD G. E., GESCHWIND I. I., 1974. Plasma luteinizing hormone, folliclestimulating hormone and prolactin during pregnancy in the mouse. Endocrinology, 94, 112116.

NOIROT E., 1972. The onset and development of maternal behavior in rats, hamsters and mice. In LEHRMAN D. S., HINDE R. A., SHAW E., Advances in the study of behavior, Vol. 4, Acad. Press, N. Y. 
NUMAN M., ROSENBLATT J. S., KOMISARUK B. R., 1977. The medial preoptic area and the onset of maternal behavior in the rat. J. comp. physiol. Psychol., 91, 146-164.

PEPE G., ROTHCHILD I., 1974. A comparative study of serum progesterone levels in pregnancy and various types of pseudopregnancy in the rat. Endocrinology, 95, 275-279.

RICHARDS M. P. M., 1969. Effects of oestrogen and progesterone on nest building in the golden hamster. Anim. Behav., 17, 356-361.

ROSENBLATT J. S., 1975. Pre-partum and post-partum regulation of maternal behaviour in the rat. In Parent-infant interaction, Ciba Found. Symp., № 33, Assoc. Sci. Publ., Amsterdam.

ROSENBLATT J. S., SIEGEL H. I., 1975. Hysterectomy-induced maternal behavior during pregnancy in the rat. J. comp. physiol. Psychol., 89, 658-700.

ROSENBLATT J. S., SIEGEL H. I., MAYER A. D., 1979. Progress in the study of maternal behavior in the rat : hormonal, nonhormonal, sensory, and developmental aspects, 225-311. In ROSENBLATT J. S., HINDE R. A., BEER C., BUSNEL M.-C. In Advances in the study of behavior, Vol. 10, Acad. Press, New York.

SHAIKH A. A., 1971. Estrone and estradiol levels in the ovarian venous blood from rats during the estrous cycle and pregnancy. Biol. Reprod., 5, 297-307.

SIEGEL H. I., DOERR H., ROSENBLATT J. S., 1978. Further studies on estrogen-induced maternal behavior in hysterectomized-ovariectomized nulliparous rats. Physiol. Behav., 21, 99-103.

SIEGEL H. I., GREENWALD G. S., 1975. Pre-partum onset of maternal behavior in hamsters and the effects of estrogen and progesterone. Horm. Behav., 6, 237-245.

SIEGEL H. I., GREENWALD G. S., 1978. Effects of mother-litter separation on later maternal responsiveness in the hamster. Physiol. Behav., 21, 147-149.

SIEGEL H. I., ROSENBLATT J. S., 1975a. Hormonal basis of hysterectomy-induced maternal behavior during pregnancy in the rat. Horm. Behav., 6, 211-222.

SIEGEL H. I., ROSENBLATT J. S., 1975b. Estrogen induced maternal behavior in hysterectomizedovariectomized virgin rats. Physiol. Behav., 14, 465-471.

SIEGEL H. I., ROSENBLATT J. S., 1975c. Progesterone inhibition of estrogen-induced maternal behavior in hysterectomized-ovariectomized virgin rats. Horm. Behav., 6, 223-230.

SIEGEL H. I., ROSENBLATT J. S., 1978. Duration of estrogen stimulation and progesterone inhibition of maternal behavior in pregnancy-terminated rats. Horm. Behav., 11, 12-19.

STERN J. M., 1977. Effects of ergocryptine on post-parfum maternal behavior, ovarian cyclicity and food intake in rats. Behav. Biol., 21, 134-140.

TERKEL J., ROSENBLATT J. S., 1968. Maternal behavior induced by maternal blood plasma injected into virgin rats. J. comp. physiol. Psychol., 65, 479-482.

TERKEL J., ROSENBLATT J. S., 1972. Humoral factors underlying maternal behavior at parturition : cross transfusion between freely moving rats. J. comp. physiol. Psychol., 80, 365-371.

VOCI V. E., CARLSON N. R., 1973. Enhancement of maternal behavior and nest building following systemic and diencephalic administration of prolactin and progesterone in the mouse. J. comp. physiol. Psychol., 83, 388-393.

ZARROW M. X., GANDELMAN R., DENENBERG V. H., 1971. Prolactin : is it an essential hormone for maternal behavior in mammals? Horm. Behov., 2, 343-354. 